the US Air Force something interesting to do with all the equipment it has manufactured. But for the rest, there is a great need for a sober and balanced programme of research. The chances are that this is what Dr DuBridge will be pushing for. There will be lots of people on his side.

\section{SCIENCE POLICY}

\section{Growth Ahead in Canada}

The Science Council of Canada clearly believes in getting its opinions off its chest before it publishes the figures which back them up. The document published some months ago which gave guidelines for Canadian science policy has now been followed by a valuable collection of statistics, prepared by R. W. Jackson, D. W. Henderson and B. Leung of the Science Secretariat. The study falls into three parts: the supply of qualified manpower, the inflation-sophistication factor, and estimates of the gross expenditure on research and development in Canada until the year 1978.

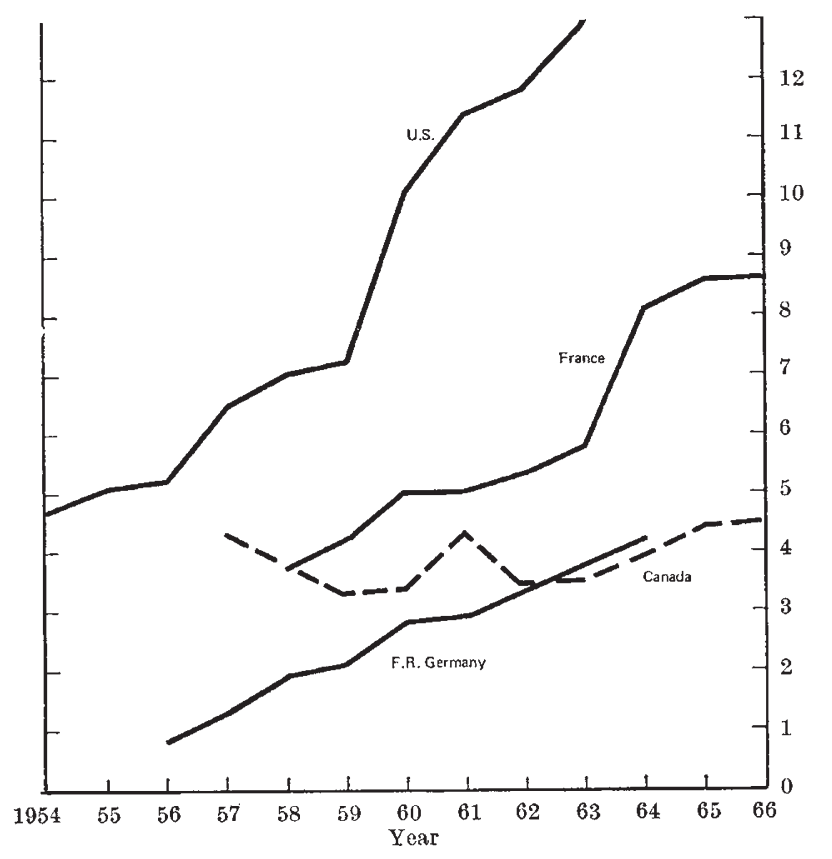

The figures suggest that this year a total of 10,760 Canadian students will graduate with a degree in science, mathematics, or engineering, out of a total graduation of 58,300. By 1977-78, the numbers will be swollen to 20,000 , from a total of 115,000 graduates. To this will have to be added the substantial net immigration of scientists and engineers which has been a feature of the past few years; in 1966, for example, Canada gained just over 3,000 scientists and engineers by immigration, over a third of the number graduating. The report suggests that from 1970, net immigration will represent about 20 per cent of the numbers graduating, but this figure is clearly subject to a great deal of uncertainty - the course of the Vietnam War, for example, could be a very significant factor. Another uncertainty is whether Canada will experience the swing away from science which has been observed elsewhere; the report concludes that so far there is no evidence for a pronounced shift in the total numbers reading for science and engineering. Within the total, however, there are shifts out of engineering and into pure science.

The section of the report devoted to calculating the "sophistication-inflation factor" for Canadian research relies heavily on reports published elsewhere. Canadian science statistics have not been sufficiently reliable to enable a characteristically Canadian figure to be extracted, but it is probably fair to assume that Canada will follow the United States pattern. The authors conclude that the costs of research and development will grow at the rate of 6 per cent a year over the next few years, a figure which takes into account both inflation and the growth of sophistication; roughly one third of this annual increase is attributed to inflation and the rest to sophistication. If anything, the authors say, this figure is likely to prove conservative.

The manpower predictions and the rate at which research becomes more expensive come together in the third section of the report, which attempts to predict gross expenditures on research and development in Canada projected to 1978 . It is first assumed that the GNP will continue to grow at around 5 per cent a year until 1970 , and $4 \cdot 75$ per cent a year after that, giving a GNP of $\$ 127.7$ thousand million in 1978. By taking an arbitrary proportion of this and devoting it to research and development, a series of very simple trends can be drawn as extrapolations of the present growth curve. These show, for example, that if $R$ and $\mathrm{D}$ is to represent 5 per cent of the GNP in 1978, it will have to grow at a rate of 19.2 per cent per year. A more likely prediction-that $\mathbf{R}$ and $\vec{D}$ costs will represent 3 per cent of the GNP-implies a growth rate of 14.2 per cent (compared with an average since 1957 of 11.0 per cent). An alternative approach is to make estimates of the proportion of the qualified manpower which will be engaged on research and development, and then to calculate what will be needed to support these numbers at any point in the future. As things are, $14 \cdot 3$ per cent of Canadian scientists are engaged on research and development; if this proportion is maintained, it will imply a rate of growth of expenditure of $14 \cdot 6$ per cent a year, to a total of about $\$ 4$ thousand million by 1978 . If the number of scientists in research and development is expected to increase to, say, 17 per cent of all scientists, this would call for a growth rate in financial terms of $16 \cdot 2$ per cent a year, and would have Canada spending nearer $\$ 5$ thousand million by 1978 . If as many as 30 per cent of all scientists were in research and development, the budget by 1978 would be $\$ 8$ thousand million, no less than $6 \cdot 2$ per cent of the GNP, a level which most people (though not the authors of the study) consider improbable. But some growth is clearly vital; the report publishes curves which show that Canadian expenditure on $\mathrm{R}$ and $\mathrm{D}$ as a proportion of total federal expenditure has actually declined since 1957, an experience shared by few other advanced countries.

\section{EARTH SATELLITES}

\section{Sutellites Applied}

Fears that a two year study of applications satellites carried out by the US National Research Council would 